University of South Carolina

Scholar Commons

$1-2008$

\title{
Research on Effective Teaching in Elementary School Physical Education
}

Judith E. Rink

University of South Carolina - Columbia, jrink@mailbox.sc.edu

Tina J. Hall

University of South Carolina - Columbia, tinahall@mailbox.sc.edu

Follow this and additional works at: https://scholarcommons.sc.edu/pedu_facpub

Part of the Education Commons

\section{Publication Info}

Published in Elementary School Journal, Volume 108, Issue 3, 2008, pages 207-218.

http://www.journals.uchicago.edu/toc/esj/current

(C) 2008 by University of Chicago Press

This Article is brought to you by the Physical Education, Department of at Scholar Commons. It has been accepted for inclusion in Faculty Publications by an authorized administrator of Scholar Commons. For more information, please contact digres@mailbox.sc.edu. 


\section{Research on Effective Teaching in Elementary School Physical Education}

\author{
Judith E. Rink \\ Tina J. Hall \\ University of South Carolina
}

The Elementary School Journal
Volume 108 , Number 3
(C) 2008 by The University of Chicago. All rights reserved.
$0013-5984 / 2008 / 10803-0006 \$ 10.00$

\begin{abstract}
The perspective of this article is that the purpose of the elementary physical education program is the development of a physically active lifestyle. We discuss the relative contribution of the development of motor skills, fitness, content related to encouraging participation, and the affective goals of the program to the development of a physically active lifestyle. Teaching must be effective if children are to acquire the skills to lead a physically active lifestyle. We explore the research base identifying effective teaching in an elementary school physical education setting in terms of academic learning time and management roles and communication and content-development skills of the teacher. Similarities and differences between teaching in a gymnasium and in a classroom are identified.
\end{abstract}

Perhaps at no point in U.S. history has it been more important that school physical education programs be effective. Next to smoking, lack of physical activity has been the major contributor to a growing epidemic of chronic and preventable disease in the United States (U.S. Department of Health and Human Services, 1996). Accordingly, the goal of a good physical education program is to propel children toward adoption of a physically active adult lifestyle.

Not only have physical educators achieved consensus on that outcome as a major part of the rationale for instruction in their subject area, the general public and related health organizations are now looking to physical education programs to contribute substantially toward achievement of that goal. Increasingly, then, physical education programs and physical education teachers will be considered effective to the extent that they not only contribute to the proximal goals of children's physical 
THE ELEMENTARY SCHOOL JOURNAL

activity and health during the elementary school years but also to the more distal outcomes of how those children elect to live their lives as adolescents and adults.

The effective physical education program targets the development of a physically active lifestyle directly. It does so by providing an instructional program that is aimed at acquisition of the skills, knowledge, and dispositions that make volitional engagement in moderate to vigorous physical activity both possible-and probable. Thus, the effective teacher in elementary school physical education has a clear intention to promote learning outcomes related to a physically active lifestyle, designs learning experiences to reach those outcomes, and assesses the extent to which those outcomes have been achieved. Those pedagogical steps, of course, are characteristics of effective teaching regardless of subject matter. Historically, however, the education community has expected less from physical education. They should not.

\section{Effective Programs}

The U.S. national content standards for physical education target six areas critical to the development of a physically active lifestyle (National Association for Sport and Physical Education [NASPE], 2004). Effective programs develop motor skills, impart knowledge needed for a physically active lifestyle, encourage regular participation in physical activity, facilitate the development and maintenance of fitness, cultivate responsible personal and social behaviors, and help students to value participation.

Although the standards represent professional consensus on educating students for a physically active lifestyle, the extent to which each area of emphasis contributes to the achievement of this goal is a current source of inquiry in the field. The profession continues to debate the relative contributions of motor skills, knowledge, fitness, and affective dispositions to the long-term goals of the field.

\section{Motor Skills}

Recent research identifies several factors that play a major role in determining the degree to which children, youth, and adults are inclined to lead a physically active lifestyle. Among the strongest of those factors are competence at performing and confidence in using motor skills, both of which are established through early experiences in physical activity and sport (Solmon, 2003). In consequence, the national professional organization for physical educators, the $\mathrm{Na}$ tional Association for Sport and Physical Education (NASPE), as well as the federally sponsored Centers for Disease Control and Prevention (CDC) have recently advocated for strong physical education programs that not only provide students with positive experiences in physical activity but also with instructional programs that actually teach students the skills they will need to lead a physically active lifestyle (Centers for Disease Control and Prevention, 2006; NASPE, 2004; NASPE \& American Heart Assoc., 2006).

Adult opportunities for physical activity vary widely, ranging from participation in sport and other recreational activities, to jogging, fitness exercises, and physical work in both the home and employment settings. It is not surprising, then, that patterns of engagement in physical activity also vary widely among individuals. Overall, however, we can predict with fair confidence which adults will adopt the constituent exercise habits that become a way of living-an active lifestyle.

In short, the most active adults are also likely to be those who have participated in structured sport or physical activities as children and youth. And it follows that because school-based physical education is the only universally shared experience of that kind in our culture, it has the potential to assume a central role in shaping the place physical activity occupies in our lives.

The first priority of an effective elementary school physical education program is to provide children with the simple motor 
skills needed to be full and enthusiastic participants in the physical play forms of childhood. Beyond that, however, most adolescent and adult physical activities require complex skills. Accordingly, preparation for adolescent and adult participation involves laying a foundation of fundamental motor skills that subsequently can be developed into activity-specific patterns. Preparation for a lifetime of participation also requires building confidence in participation-the belief that skills can be successfully performed and, when needed, that new skills can be acquired.

Physical educators usually refer to these foundational skills as fundamental motor skills. Fundamental motor skills include locomotor patterns (skipping, hopping, jumping, etc.), manipulative patterns (throwing, catching, striking, and receiving objects), and body-management skills (balancing, rolling, transferring the weight of the body) (Graham, Holt/Hale, \& Parker, 2004). In effective programs, children move from immature versions of these patterns to mature versions and begin to use them in more specialized settings. These are not the highlevel skills of the athlete but rather the essential building blocks for a life of physical activity.

Although some students clearly gain competence and confidence in motor skills outside the school setting, the elementary physical education program is responsible for the development of these skills with all children. Although it is not yet clear how various aspects of physical education can be shaped to best contribute to a physically active lifestyle, we can be very clear about what appears to impede such an outcome. Ineffective programs run the gamut from those emphasizing specialized sport skills rather than fundamental motor skills, on the one hand, to those, on the other hand, that teach no skills at all. The latter consist mostly of low-organizational games or "fun" activities that engage children but do not educate in any systematic sense.

Further, teachers who allow their classes to contain conditions that erode rather than enhance children's confidence in their ability to learn and perform physical activities are detrimental to the acquisition of positive attitudes about exercise. Tasks that make demands exceeding the present movement capabilities of a child yield only repeated failure. Likewise, moving instruction forward through a series of tasks for which a child does not have sufficient practice time to achieve mastery results only in an accumulation of failures. Whether due to inappropriate tasks or inadequate opportunity to practice, the end result is children who lose confidence in their ability to learn and perform. They often learn to feel helpless when confronted by even simple motor skills. The prospect that they will wish to include such failure-loaded physical activities in their pattern of daily activity is dim, at best. Effective teachers not only must have a clear vision of the developmentally appropriate repertoire of motor skills that all children should learn, they must also devise lesson structures that truly do allow no child to be left behind.

\section{The Role of Fitness}

Fitness has often been viewed by the public as "the" singular product of physical education programs. Indeed, in too many instances the success of programs has been evaluated solely in terms of the degree to which students perform well on tests of physical fitness. Because there is not a strong relationship between fitness and a child's characteristic level of physical activity, fitness tests offer only a weak indicator of success in the work of encouraging physically active lifestyles.

In contrast with widely held public assumptions about fitness, most physical educators turn the causal model on its head. They are inclined to regard physical fitness as an outcome of a physically active lifestyle-not the reverse. That makes the attraction to regular exercise the singular product of physical education, with the corollary being that if children, youth, and 
adults can be taught how to be physically active regularly, fitness will be an outcome of that participation.

Currently, the emphasis in school programs is on fitness factors related to health (health fitness) rather than on those highly related to sport participation (performance fitness) (McKenzie, 2003). Cardiovascular endurance, flexibility, muscular strength and endurance, and body composition are usually considered the components of health-related fitness. The kinds and degrees of endurance, flexibility, and strength that support expert performance of particular sport or activity skills are the components of performance fitness.

Fitness testing and training for performance fitness are usually contraindicated for elementary-age students below the fourth grade. Fitness testing using the Fitnessgram (a test of health fitness) can begin at the fourth or fifth grade and often is used as an educational tool to help students learn about fitness and their bodies (NASPE, 2000).

Although fitness testing for young children is not advocated, students are encouraged at an early age to understand the health benefits of being physically active. For instance, kindergarten students may begin with identifying the physiological effects of exercise on the body in terms of sweating and breathing hard. By the fourth grade, students can learn the components of health fitness and how each might be developed.

\section{Participation in Physical Activity}

To be effective in the promotion of participation in physical activity, elementary school programs must use both time in the physical education class and time outside of the physical education class. If elementary students are to receive the recommended 1 hour of moderate to vigorous physical activity (MVPA) a day, only the rare physical education program has sufficient class time to provide that amount. Most programs meet for much shorter periods of time, and classes occur only intermittently. Accordingly, school time allotted for recess, time before and after school, movement opportunities integrated within classroom experiences, time getting to and from the school, and time spent with parents and peers after school and on weekends must all be potential targets for planned experiences in physical activity (Woods \& Graber, 2007).

It follows naturally, then, that physical education teachers cannot be the only persons responsible for planning and supervising children's physical activities. A significant commitment to promoting physical activity requires the collaboration of classroom teachers, administrators, parents, and the community. Further, in some schools the physical education teachers are ideally positioned to coordinate efforts across the school curriculum and outward into homes and the wider community. Physical education classes will contribute whatever the school schedule may allow to children's daily ration of physical activity, but the work of many physical education specialists no longer will end at the gymnasium door.

\section{Affective Goals}

National content standards for physical education include two objectives in the affective domain. The first describes an outcome consisting of responsible personal and social behavior in physical activity settings. The second relates to the goal of helping students value physical activity. Physical educators have always seen their subject area as a laboratory ideally suited for the development of "character" and social skills. The cooperative and sometimes competitive nature of physical education provides opportunities for teachers to teach to these objectives directly. Opportunity, however, does not always translate into practice.

In relation to the first affective objective, developing desirable social behaviors, the simple placement of students into learning contexts that have some potential to promote affective outcomes does not, in itself, 
assure that the desired learning will occur. Although experiences in physical education present opportunities for the inculcation of many positive personal and social behaviors, they also have the potential to develop negative behaviors. Effective instruction targets the positive behaviors the teacher wishes to develop and attends to them directly rather than relying on the assumption that such learnings will somehow be an automatic outcome of the program.

The second affective content standard, helping students to personally value physical activity, may be the most important of the NASPE standards related to lifetime physical activity, but it also is by far the most difficult to achieve. The problem here rests in the highly individual nature of human perception and motivation.

People participate in physical activity for a variety of reasons. Although the general public acknowledges the health benefits of participation, and health benefits are a desired outcome of participation, most people do not participate in physical activity because of health benefits. Rather, they participate because they enjoy social interaction with others, the challenge of the activity, the opportunity to express themselves, or the simple joy to be found in the play and rhythms of movement. As a result, what makes achieving this standard difficult is that the reasons for participation are highly individualized.

Meanings and experiences that are enjoyable in a physical activity for one student may not resonate at all for another (Jewett \& Mullan, 1977). Maintaining a positive class atmosphere, concentrating on individual development rather than comparison of performance among children, and offering a rich variety of movement forms are all ways of potentially investing physical activity with value. Nevertheless, there is no sure and certain pedagogy that will make every activity attractive and ultimately habitual for every student.

It is not surprising, then, that the recent emphasis on the development of a physi- cally active lifestyle has caused physical educators to focus on the needs and interests of students who have not been well served by traditional emphases on sport, and, particularly, on team sports. Modern curriculum content reflects an effort to expand the menu of physical activities as a means of better serving a diverse student population. Effective high school programs offer students the opportunity to choose activities they find enjoyable; however, it is the role of the elementary program to ensure that a wide variety of introductory experiences in different kinds of physical activity (dance, games, and gymnastics) are provided. All students should master the fundamental skills that support performance in many different motor activities, acquire the confident expectation that they can be successful within the limits of their physical capacity, and, above all, discover that they want to continue with something that can be a valuable part of each day.

\section{Effective Instruction}

The literature that describes the effective classroom teacher also describes the effective physical education teacher in the elementary school. The "classroom" of an effective elementary physical educator, whether it is a gymnasium, multipurpose room, or outdoor movement space, is a positive and stimulating learning environment. It is well organized, expectations are clear, and the teacher is consistent in enforcing and maintaining behaviors conducive to a quality learning environment. Unlike play and recess activities, students are engaged at a high level in learning lesson content for a large part of each class period.

The physical educator's working environment, however, can be vastly more complex than that of the classroom teacher. For example, the teaching area is larger, the students are moving the majority of the time, a variety of large and small equipment is in use, the teacher-to-student ratio is often higher than that of the classroom teacher, and physical safety is always a concern. 
Nevertheless, although the context may be different, the variables related to teaching effectiveness and the instructional skills necessary to produce learning in the gymnasium are similar to those needed in the classroom (for extensive reviews of the literature see Graber, 2001; Lee 2003).

High Engagement in Content

Early investigations identifying effective teaching skills in physical education, like the literature on effective classroom teaching, quickly identified the amount of time students spend with content as the single most critical variable related to whether or not students learn in physical education. Motor skills are learned when they are placed into long-term memory, which makes practice one of the most critical variables in learning these skills. After setting aside some important codicils, there remains a useful general rule-more practice produces more learning.

The original work with Academic Learning Time-Physical Education (ALTPE) demonstrated only a low positive relation between simple measures of time-ontask and student learning of motor skills in physical education (Silverman, 1991). Later research on ALT-PE, however, introduced and refined the concept of appropriate practice, which introduced qualifications such as "practice with adequate levels of feedback" and "practice with high rates of success" that were required to make practice a powerful agent in learning (Silverman, 1993).

Several early ALT-PE studies also revealed that in typical physical education settings students were only engaged in appropriate forms of practice about one-third of the class time (Silverman, 1991). The other two-thirds of time was typically spent in organization and management activities and passive listening to verbal instruction. Most commonly, observations revealed that students spent far more time waiting their turn to practice than being engaged directly in class content.

Largely as a result of those disturbingly graphic displays of inefficient management and ineffective pedagogy, today's effective teacher is defined as one who has the skills needed to minimize unengaged student time and maximize the time devoted to active and appropriate learning. This means that teachers must be good managers, that they present material clearly to students, select developmentally appropriate content, and develop lessons that produce both learning and positive tendencies toward participation.

Managing People, Equipment, Space, and Time

Physical education teachers must manage people, equipment, space, and time for efficient learning. Students waiting for their turn to practice is a characteristic of ineffective teaching. Waiting in line and sharing equipment in physical education are the equivalents of students sharing a pencil or book in the classroom. Whether the source of the problem is the poor organizational skills of the teacher, inadequate equipment, or a poor choice of a learning experience used to practice the content, the result is lack of practice and, therefore, learning.

Organizing and managing a physically active class on a blacktop area, a grassy field, or in a multipurpose room or gymnasium is far more complicated than that of the classroom where children are sitting at desks. In a physical education environment, the boundaries for student action often are undefined and change with differing tasks. In addition, the use or change of equipment from one task to another is more complex than in a classroom setting. Each of these shifting variables has the potential to consume valuable time. Effective teachers know how to anticipate events, make smooth transitions, and maximize ALT-PE.

One key to effective organization for the physical education teacher is the use of established routines for students entering and leaving class, for selecting and putting away equipment, for starting and stopping a task, for handling equipment when the 
teacher is talking, and for coming together for instruction and task presentation. An effective teacher has established routines for all basic managerial tasks and uses clear signals for stopping and starting activity.

Maintaining a Learning Environment

Classroom management and discipline are often major concerns for teachers and principals because of their potential to decrease student learning and erode teacher morale. Prevention is the key to discipline both in the classroom and in the gymnasium, and the keys to prevention are clear expectations and close teacher monitoring.

Students of an effective teacher clearly understand the expectations for their behavior. They are aware of what is acceptable and know the consequences for unacceptable behavior. They do not, however, learn all of that simply by the process of misbehaving and then suffering the aversive consequences. Standards for behavior are established by explicit instruction during the earliest meetings of the class. The managerial and disciplinary regimens of an effective teacher can then be sustained by interacting with students to reinforce positive behavior and to extinguish negative behavior in a fair and consistent manner.

Physical education teachers play an active monitoring role in every lesson. In the physical education environment students are moving the majority of the time. Teachers need to be able to handle several events simultaneously, be aware of all that is occurring around them, and anticipate any behaviors that might be inappropriate or present potential safety issues. The teacher must be effective at visual scanning, using physical proximity to control students, moving easily among the students, and providing feedback to individuals or groups while simultaneously monitoring the entire class.

Quality of Practice, Success Rate, and Student Interest and Motivation

One reason that time spent in practice, by itself, cannot predict learning is that the quality of practice is just as important as the amount of practice. Quality practice can only occur if students are practicing tasks related to the learning goal at an appropriate level of success. Unlike cognitive tasks, an appropriate level of success for motor skills varies with the skill. Motor-task performances generally are more variable in their demands. For example, even a professional basketball player would not be expected to achieve a perfect level of success in a free throw. In contrast, it is not unreasonable to expect a fourth-grade student to be able to do repeated forward rolls with a level of consistency. Teachers must find a level of success for each task that is challenging but achievable. Tasks can be inappropriate because they are too difficult, but they can be just as inappropriate if students are not challenged and the tasks are too easy.

Motivation to be engaged in motor tasks is highly related to both success in past performance and a student's perception of that success. Students can use either their own improvement as a measure of success ("I am getting better at this") or the quality of their performance relative to that of others in the class ("I am better at this than they are"). The consequences of those two ways of calculating success, however, can have an important influence on student learning in the context of physical education.

Recent research on the construct of egoorientation (centering on comparison of the self versus others) and task-orientation (focusing on how the self progresses at mastery) propensities of students in physical education has led to the recommendation that physical education teachers direct their teaching toward encouraging students to use a task rather than ego orientation (Solmon, 2003; Xiang \& Lee, 2002). A task orientation has the potential to help students personalize their notion of success and avoid external comparisons that are not relevant to their own achievement. When children compare their performance to their own previous attempts, they often can ob- 
serve that practice pays off. The same degree of improvement, however, might seem inadequate if the only basis for judgment is comparison to the performance of other children.

On their own, of course, some children will make comparisons (especially higherskilled students). An effective teacher, however, downplays such comparisons or gives children a choice of whether or not to be competitive in judging their performances rather than forcing all children into such situations.

One problem physical educators face is that of individualizing tasks for different skill levels so that each student experiences an appropriate level of challenge and success. Teachers do this for many skills in physical education through changes in equipment (i.e., larger, smaller, lighter, heavier), choice of distances that change the force production requirements of a skill, changing the height of targets (i.e., using an 8-foot versus a 9-foot high basketball goal), and allowing students to choose whether to work with a partner cooperatively or competitively. Although many of these choices can be child directed, an effective teacher will guide low- and averageskilled students to more successful practice situations and, at the same time, challenge high-skilled students by inviting them to try a more difficult challenge.

\section{Effective Communication}

In many lessons conducted by a classroom teacher, verbal instruction may consume a large part of the lesson. In physical education, however, verbal instruction must be brief and clear if valuable time for active practice is to be preserved. Once the task is established, children learn by moving-not by listening. Student-teacher interactive behavior in the classroom is likely to involve the teacher asking questions and the students responding to those questions; however, in the gymnasium, interactive discourse often involves the teacher presenting movement tasks and students responding motorically. As in the academic classroom context, however, the success of the student response will be highly related to how clearly the teacher presents the task.

Although achieving proficiency in motor skills ultimately relegates motor responses to the level of automatic neural control, the first stage in learning a motor skill requires active cognition. When students are sent off to practice a movement task the teacher assigns, they need to have a "motor plan," and that image of intention is established through clear verbal presentations and explicit modeling by the teacher.

Because clear task presentations are so critical to learning motor skills, physical educators have identified characteristics of good task presentations. A solid task presentation requires the teacher to obtain the students' attention, sequence the content and organizational aspects of the task, communicate tasks verbally as well as through demonstrations, use a variety of approaches to communicate information, use both examples and nonexamples of good performance, personalize the presentation to students, repeat difficult parts, and check for understanding (Rink, 2006).

One of the most important skills of the physical education teacher is the ability to identify critical features of a skill. To do this, teachers not only need to know the content they are teaching but also which elements of content are critical for skill acquisition at beginning, intermediate, and advanced levels of learning. Further, they must make that discrimination not simply for learners in general, but for each student or class of students. That is, effective teachers must be able to select and emphasize critical features that are appropriate for learners with particular developmental ages, experience, and motor ability.

Identified critical features of motor skills are often communicated in a task presentation through the selection of a few critical cues and the use of a demonstration. Learning cues are an abbreviated form of the critical features of a task (e.g., the word "squash" 
when a teacher wants students to simultaneously flex at the hips, knees, and ankles) that the learner can use to establish an accurate motor plan (Rink, 2006). Teachers can use learning cues as students "rehearse" a skill in the beginning stages of learning.

Elementary students rely heavily on visual information, making accurate visual demonstrations critical to the presentation of motor content. Good skill demonstrations require particular presentation skills so that the demonstration does not communicate the wrong information. During a demonstration, an effective teacher shows the desired performance stripped of all unessential components, at both natural and slower speeds of execution, while verbally emphasizing only the important performance cues for the task.

\section{Developing Content}

An effective physical educator is goal driven and plans well beyond daily lessons. Planning begins with mapping the curriculum across the grade levels, follows with a yearly plan, and then proceeds with the development of unit and lesson plans. Key to a unit or lesson plan is the development of content based on instructional objectives as well as on the needs and abilities of students.

Learning tasks designed by an effective physical educator have an objective and are related to objectives of the lesson and unit. Effective teachers facilitate learning by developing content with a progression of tasks that lead learners toward a higher level of competency. A quality task progression sequences learning experiences from simple to complex, focuses the learner on how to achieve improved performance, and provides many opportunities for children to assess and apply the learned skills (Rink, 2006).

Teachers can present content effectively through a task progression by using four types of tasks: informing, extension, refinement, and application/assessment. The informing task is the initial task of the skill progression. Extension tasks are then used to increase or decrease the complexity (and thus the difficulty) of the task. Extension tasks in physical education often manipulate task conditions. For example, students can catch a ball tossed to them from a short distance as the basic informing performance and then be challenged to catch a ball while on the move as an extension task.

Typically, teachers increase the difficulty of a task when student success warrants a greater challenge. At other times, a decrease in difficulty might be necessary if the previous task was too challenging for most students. It is also possible to have a lateral extension that changes the task conditions but not the level of difficulty.

The teacher's intent for good performance is made clear through the use of refining tasks, which are used to focus or refocus students on a quality of the movement. An effective teacher is able to observe students practicing, analyze their movement, and provide cues that will help them concentrate on an aspect of the movement that will lead to a more efficient motor pattern. Application/assessment tasks require students to use a newly acquired skill in cooperative, competitive, or performance contexts. Teachers can introduce tasks of this kind once learners begin to display basic competence and show some confidence in their level of mastery.

Instruction in physical education is largely a dynamic process. There are no permanent products in physical education. In other words, the teacher must rely on the direct and immediate observation of student performance to make decisions about what to do next. During a lesson, an effective teacher is constantly observing children and asking, (a) Is the task appropriate for the motor and cognitive level of most of the class? (b) Is it time for an extension? (c) Should the task just be changed for a few students? (d) Is there a need to refine part of the movement by providing another learning cue? and (e) Are students ready to apply the skill? In essence, effective teachers adjust or mod- 
ify tasks in response to how students respond. After the lesson, the teacher reflects and decides how to develop the content for the next lesson. Content development, therefore, is ongoing.

\section{Teacher Feedback}

Teacher feedback provides information to learners about their performance that they cannot receive from other sources. In contrast to the academic classroom, where relatively little of the teacher's feedback is given concurrent to performance, in physical education feedback must be provided when the student is actually doing the task or immediately after. Such "in-process" feedback requires acute skills of observation and the capacity to instantaneously sort important from unimportant in what has been displayed.

The ability to provide relevant feedback generally is regarded as a key aspect of effective teaching. The actual effect that feedback has on learning is influenced by many factors, such as the skill and knowledge base of the students to whom feedback is directed, the type of skill being performed, the type of feedback the teacher provides, and the motive behind the teacher's feedback (Magill, 1994). In some situations the task itself can provide sufficient intrinsic feedback, thereby minimizing the need for augmented feedback from the teacher. The lower the skill level of a child, the more benefits he or she receives from feedback. If a skill is new to a child, prescriptive information that enables the learner to determine what needs to be done for performance improvement is important to facilitate learning. Augmented feedback becomes more essential when the learner lacks prior knowledge about the relationship between the intent and the movements required to achieve that purpose.

The type of feedback an effective teacher uses has different purposes based on the motive behind its use. Typically, when teachers provide feedback, they are informing the student that the action exhibited is either acceptable or needs modifying. The idea is for the learner to make the changes in the practice trials that follow. Quality of the feedback is more important than quantity. Although younger children welcome a teacher's attention, it is imperative that the teacher design the instructional environment so that students will not become dependent on augmented feedback. Effective teachers use a variety of means to provide feedback other than just teacher to student (e.g., video replays, peer evaluation, and self-assessment).

\section{Classroom Teacher versus Specialist}

Although physical education specialists teach most physical education programs at the secondary level in the United States, often that arrangement does not exist in elementary schools. Although the arrangement varies somewhat from state to state, untrained classroom teachers in some school systems often are expected to provide all or at least some instruction in physical education.

To the extent that physical education programs have the objective of encouraging adoption of a physically active lifestyle, qualified physical education teachers are essential. Central to that judgment is the fact that specialists display more effective teaching behaviors (Faucette \& Patterson, 1990). Explicitly, teachers who have been prepared and licensed to teach physical education have specialized knowledge of movement skills, observational skills that help them make appropriate decisions about student performance, an understanding of the risks and benefits of participation, and an understanding of how to develop and maintain productive learning in a highly fluid and fast-moving environment. Research on learning outcomes in programs taught by specialists and nonspecialists overwhelmingly supports of the presence of specialists. Students in classes taught by specialists achieve more, have higher fitness levels, and exhibit a more positive attitude toward 
physical activity (Rahim \& Marriner, 1997; Sallis et al., 1997).

\section{Assessing Program Quality}

Historically, elementary physical education programs have largely been left untouched by efforts to evaluate their effectiveness or to hold schools or teachers accountable for providing students with effective instruction. Many states have approved curriculums with no accountability for whether or not they are implemented. State mandates have, for the most part, identified minimum time requirements or provided a minimum student to teacher ratio to assure that physical education was being taught. More recent efforts have involved assessing the written curriculum or the extent to which students are competent in the state standards.

The CDC recently released the Physical Education Curriculum Assessment Tool (Centers for Disease Control and Prevention, 2006). This tool was designed to evaluate the extent to which the written physical education curriculum is consistent with the national physical education standards. The tool addresses the following questions:

- Does the program address the national/state standards?

- Are the goals and objectives of the program clearly stated?

- Is there an articulated scope and sequence to the program?

- Is the content of the curriculum developed in a developmentally appropriate way?

- Are the goals and objectives of the program achievable within the time and with the resources available?

- Is enough detail provided so that unit development would have a clear direction?

- To what extent is both formative and summative assessment integrated throughout the curriculum?

Many states have adapted or adopted the national content standards for physical education. A task force assembled by NASPE, the professional organization that sets the standards for physical education programs, is currently developing assessment materials to measure the extent to which students achieve these standards. Their approach has been to develop a set of critical performance indicators for each of the six standards at the kindergarten, second-, and fifth-grade levels and assessment materials for those performance indicators that schools, districts, and states can use to determine student competence.

Although some districts and states have required assessment in physical education, South Carolina is, to this date, the only state that has designed and implemented a more comprehensive assessment program with legislated provisions for accountability at the school level. Specifically, the system requires an assessment of the extent to which students in a program are competent in the state's standards (which largely mirror the national NASPE standards). Then, scores for each school are reported on a publicly disseminated school report card (Rink \& Mitchell, 2003). Initial research studies support the use of assessment and accountability as mechanisms for program improvement (Rink, Jones, Kirby, Mitchell, \& Doutis, 2007; Rink \& Mitchell, 2003).

\section{Summary}

It is imperative that elementary physical education programs be both planned and taught in ways that move children toward adoption of physically active lifestyles. The key links between what we now know about effective teaching and the creation of effective programs are an adequate level of resources and the resolve of physical educators. Legislative policy makers, school administrators, and taxpayers must provide the former, and in so doing they will acquire the right to demand the latter.

Note

The authors may be contacted at the following e-mail addresses: jrink@gwm.sc.edu and tinahall@gwm.sc.edu. 
References

Centers for Disease Control and Prevention. (2006). Physical education curriculum analysis tool. Atlanta: Author.

Faucette, N., \& Patterson, P. (1990). Comparing teaching behaviors and student activity levels in classes taught by P.E. specialists versus non-specialists. Journal of Teaching in Physical Education, 9, 106-114.

Graber, K. C. (2001). Research on teaching in physical education. In V. Richardson (Ed.), Handbook of research on teaching (4th ed., pp. 491-519). Washington, DC: American Educational Research Association.

Graham, G., Holt/Hale, S. A., \& Parker, M. (2004). Children moving: A reflective approach to teaching physical education (6th ed.). Boston: McGraw-Hill.

Jewett, A., \& Mullan, M. (1977). Curriculum design: Purposes and processes in physical education teaching and learning. Reston, VA: American Alliance for Health, Physical Education, and Recreation.

Lee, A. M. (2003). How the field evolved. In S. J. Silverman \& C. D. Ennis (Eds.), Student learning in physical education: Applying research to enhance instruction (2d ed., pp. 9-25). Champaign, IL: Human Kinetics.

Magill, R. A. (1994). The influence of augmented feedback on skill learning depends on characteristics of the skill and the learner. Quest, 46, 314-327.

McKenzie, T. L. (2003). Health-related physical education: Physical activity, fitness, and wellness. In S. J. Silverman \& C. D. Ennis (Eds.), Student learning in physical education: Applying research to enhance instruction (2d ed., pp. 207-226). Champaign, IL: Human Kinetics.

National Association for Sport and Physical Education. (2000). Appropriate practices for elementary school physical education. Reston, VA: Author.

National Association for Sport and Physical Education. (2004). Moving into the future: National content standards for physical education $(2 \mathrm{~d}$ ed.). Reston, VA: Author.

National Association for Sport and Physical Education and American Heart Association. (2006). 2006 shape of the nation report: Status of physical education in the USA. Reston, VA: Na- tional Association for Sport and Physical Education.

Rahim, M., \& Marriner, T. (1997). Students' attitudes toward physical activity: Specialist vs. non-specialist. Alberta Journal of Educational Research, 43, 161-164.

Rink, J. E. (2006). Teaching physical education for learning (5th ed.). Boston: McGraw-Hill.

Rink, J., Jones, L., Kirby, K., Mitchell, M., \& Doutis, P. (2007). Teacher perceptions of a physical education statewide assessment program. Research Quarterly for Exercise and Sport, 78, 204-215.

Rink, J., \& Mitchell, M. (2003). State-level assessment in physical education: The South Carolina experience [Monograph]. Journal of Teaching in Physical Education, 22.

Sallis, J. F., McKenzie, T. L., Alcaraz, J. E., Kolody, B., Faucette, N., \& Howell, M. F. (1997). The effects of a 2-year physical education program (SPARK) on physical activity and fitness in elementary school students: Sports, play and active recreation for kids. American Journal of Public Health, 87, 1328-1334.

Silverman, S. (1991). Research on teaching in physical education: Review and commentary. Research Quarterly for Exercise and Sport, $62,352-364$.

Silverman, S. (1993). Student characteristics, practice, and achievement in physical education. Journal of Educational Research, 87, 5461.

Solmon, M. A. (2003). Student issues in physical education classes: Attitudes, cognition and motivation. In S. J. Silverman \& C. D. Ennis (Eds.), Student learning in physical education: Applying research to enhance instruction ( $2 \mathrm{~d}$ ed., pp. 147-164). Champaign, IL: Human Kinetics.

U.S. Department of Health and Human Services. (1996). Physical activity and health: A report of the Surgeon General. Atlanta: Centers for Disease Control and Prevention.

Woods, A. M., \& Graber, K. C. (Eds.). (2007). Stepping up to the plate: Physical educators as advocates for wellness policies-Part I [Special issue]. Journal of Physical Education, Recreation and Dance, 78(5), 17-28.

Xiang, P., \& Lee, A. (2002). Achievement goals, perceived motivational climate, and students' self-reported mastery behaviors. Research Quarterly for Exercise and Sport, 73, 5865. 